\title{
Mycobacterial infections in AIDS
}

\author{
A ROSS HILL, MD, CM
}

\begin{abstract}
AR Hill. Mycobacterial infections in AIDs. Can $J$ Infect Dis 1991;2(1):19-29. Tuberculosis (TB) remains uniquely important among acquired immune deficiency syndrome (AIDS)-associated opportunistic infections: it presents the greatest public health hazard worldwide, is the most readily curable, and is largely preventable with existing means. Given the expanding pool of human immunodeficiency virus (HIV) seropositive persons, particularly in developing nations where Mycobacterium tuberculosis remains a leading health problem, one can expect a continued rise in TB cases during the 1990s. Global efforts to eliminate TB are now inextricably entwined with the effectiveness of measures to curtail the HIV epidemic. Mycobacterium avium complex infection, currently an intractable late complication of AIDS, may increase in clinical importance as success in managing other opportunistic infections and HIV disease itself improves. Understanding of the pathogenesis and management of mycobacterial diseases should increase rapidly given the renewed research spurred on by the advent of HIV.
\end{abstract}

Key Words: Acquired immune deficiency syndrome, Human immunodeficiency virus, Mycobacteria, Mycobacterium avium complex, Mycobacterium tuberculosis, Tuberculosis

\section{Infections mycobactériennes dans le syndrome d'immunodéficience acquise}

RESUME: La tuberculose se distingue tout particulièrement parmi les infections opportunistes associées au syndrome d'immunodéficience acquise: elle présente le plus grand danger de santé publique à l'échelle mondiale; elle est également le plus aisé à traiter et sa prévention est largement accessible avec les moyens existants. A cause du nombre grandissant de sujets séropositifs, surtout dans les pays en voie de développement où Mycobacterium tuberculosis reste un problème sanitaire majeur, on peut s'attendre à l'augmentation constante des cas de tuberculose au cours de la décennie. Les efforts globaux d'éradication de la tuberculose sont maintenant inextricablement liés à l'efficacité des mesures destinées à arrêter l'épidémie causée par le virus d'immunodéficience humaine. L'importance clinique de l'infection à Mycobacterium avium complexe, qui est actuellement une complication tardive réfractaire du syndrome d'immunodéficience humaine, pourrait augmenter avec l'amélioration de la prise en charge des infections opportunistes et de la maladie VIH elle-même. Notre compréhension des affections mycobactériennes pourrait augmenter rapidement avec le renouveau des travaux de recherche qu'a provoqué l'avènement du VIH. 
W ITHIN TWO TO THREE YEARS OF THE RECOGNITION of the acquired immune deficiency syndrome (AIDS) in the spring of 1981, it became apparent that patients with this lethal form of immunodeficiency have a strong susceptibility to mycobacterial disease. Initial reports described a striking syndrome of disseminated infection due to Mycobacterium avium complex (1-6), and an increased prevalence of disease due to Mycobacterium tuberculosis (TB) was recognized soon thereafter (7-16). Within a decade, the apparently new viral agent of AIDS, human immunodeficiency virus type 1 (HIV), has altered the clinical face of TB and wrought grave changes in the global epidemiology of this millenia-old but still flourishing bacterial scourge of humans.

At least 10 other mycobacterial species are reported pathogens in AIDS patients and, like $M$ avium complex, tend to produce disseminated infection (17). Most frequent is Mycobacterium kansasii, which can cause cavitary lung disease as in non-AIDS patients (18), as well as late disseminated disease (19).

This review will compare the two most important mycobacterial agents in AIDS, $M$ tuberculosis and $M$ avium complex.

\section{EPIDEMIOLOGY}

The relative proportions of mycobacterial species cultured from AIDS patients vary widely between geographic areas, reflecting the background prevalence of latent $M$ tuberculosis infection in the local population and the frequency with which nontuberculous mycobacteria are encountered in the environment. Disseminated $M$ avium complex infection predominates in most centres in North America and is more uniform in geographic distribution than is $M$ avium complex lung disease unrelated to HIV (20). TB is more commonly recognized (and appears to be more prevalent) in many regions of the world, particularly in developing nations where the majority of persons have been infected by adulthood, and are thus at risk for reactivated disease (7,21-26). The reason for the low frequency of diagnosed $M$ avium complex infection in some countries remains unclear. Possibilities include less environmental exposure, early death from more virulent infections, difficulties in microbial diagnosis, or other unidentified epidemiologic factors. The absence of $M$ avium complex bacteremia among AIDS patients in Uganda supports a truly lower prevalence (27). The variable influence of epidemiologic factors, including endemic $M$ tuberculosis, can be observed in a single locale such as New York City, where $M$ avium complex is the most common HIV-related mycobacterial isolate in white homosexuals and hemophiliacs, whereas $M$ tuberculosis predominates in Caribbean and Hispanic immigrants and is common in native intravenous drug abusers $(11,14,16)$.

AIDS is almost certainly responsible for the recent upswing in the incidence of $\mathrm{TB}$ in the United States and in some African and Latin American nations (21-23). The relationship between TB and HIV infection has been quantified using several approaches. AIDS/TB registry matching gives a skewed underestimate of the problem, since the majority of patients with AIDSrelated TB present prior to the diagnosis of other AIDS-defining diseases (28). Even so, $4 \%$ of AIDS cases reported in the United States also had TB (29), a rate far exceeding the overall national incidence of about $0.01 \%$ of the population per year. In communities or countries where $\mathrm{TB}$ is more common, it afflicts a proportionately higher fraction of the AIDS population (Table 1).

Prospective studies of HIV seroprevalence among new TB cases reveal a more pervasive interaction (30-33) (Table 2) exceeding the proportion of TB patients with concurrent AIDS estimated by clinical criteria $(15,28)$. Geographically, seroprevalence varies in parallel with the background prevalence of HIV infection in the general population but is at least several fold higher, reflecting the extent to which HIV promotes progression to disease (22). About half of the TB patients in geographic 'hot spots' for HIV are now seropositive, signalling the need to evaluate the HIV status of all new TB patients, particularly those aged 20 to 60 years, in any community with significant endemic HIV.

Of crucial importance is the likelihood that a person with latent $M$ tuberculosis will develop TB during the course of AIDS. Though longitudinal data are scarce (34), one can estimate a cumulative probability of about 25 to $50 \%$ based upon epidemiological considerations (22), as well as TB rates reported from populations in which most adults harbour $M$ tuberculosis (21) (Table 1). The probability of progression from infection to disease is roughly sixfold greater than in the general (HIV negative) population (22). Thus HIV infection is more potent and quantitatively more important than any of the traditional risk factors for the development of TB $(22,35)$.

TB in HIV seropositive patients usually precedes other AIDS-defining diseases (28), but occasionally follows by a few months (rarely more than a year), reflecting the greater virulence of $M$ tuberculosis compared with other common opportunistic agents (Pneumocystis carinii, Cryptococcus neoformans, Toxoplasma gondii, $M$ avium and cytomegalovirus) $(11,12,14,15,21,30,31,33,36$, un- 
published data). Thus TB, like bacterial pneumonia (Streptococcus pneumoniae and others) or Herpes zoster eruption is often the first infectious complication coming to medical attention. Nonetheless, other AIDS-related diagnoses are commonly made concurrently with or within six to 12 months after the diagnosis of TB. Oral candidiasis is present when $\mathrm{TB}$ is diagnosed in 10 to $35 \%$ of cases (30-34,37), and usually signals the presence of esophageal candidiasis (38).

Circulating CD4+ T lymphocytes in HIV seropositive TB patients are virtually always reduced, numbering less than $400 / \mathrm{mm}^{3}$ in the majority as reported from several nations. Counts are less than $200 / \mathrm{mm}^{3}$ (often less than $100 / \mathrm{mm}^{3}$ ) in patients with lymphatic or other extrapulmonary dissemination (31), while higher counts may be found with localized pulmonary disease (33). Thus, a moderate to severe reduction in $\mathrm{T}$ helper cells seems required before clinical disease develops in these patients (39), who are otherwise at an age of low risk for TB. Though most are entering the final phase of HIV disease (usually WalterReed stages 4 to 5), it is evident from serologic screening that a small minority can remain asymptomatic for two or more years after treatment for TB, a fraction of which may increase as new therapies extend the survival of AIDS patients.

Epidemiologic patterns (Table 1), the increased rate of extrathoracic presentations, and the fairly consistent temporal relationship of TB to other opportunistic infections caused by latent organisms all strongly suggest that most HIV-related TB represents reactivated infection $(21,36)$, parallelling the conventional attribution of $90 \%$ or more of adult cases in the United States. Prospective data in drug addicts positive for purified protein derivative of tuberculin support this supposition (34). However, since immunodeficiency promotes progression to disease, and since most cases come from communities with an increased prevalence of $\mathrm{TB}$, an unquantified minority of cases may represent uncontrolled primary infection (39). Moreover, weakening of the secondary immune response may also permit reinfection with consequent disease, a possibility difficult to document without phage typing or DNA 'fingerprinting'.

The likelihood of transmitting TB to contacts does not differ greatly between AIDS and non-AIDS patients, even though cavitary disease is less frequent in the former $(24,30,35,40)$. Countervailing factors such as more extensive parenchymal and endobronchial disease or impaired killing of bacilli within noncavitary lesions may contribute to sputum smear positivity in AIDS. Sputum cultures are positive nearly as often as in non-HIV patients $(15,30,32,33)$.
TABLE 1

Prevalence of tuberculosis in patients with clinically defined acquired immune deficiency syndrome

\begin{tabular}{lcc}
\hline Geographical source (reference) & Years & $\begin{array}{c}\text { Percentage } \\
\text { with TB }\end{array}$ \\
\hline United States (29) & $1981-88$ & 4 \\
New York City, New York (14) & $1979-85$ & 8 \\
New York City, New York (12) & $1981-84$ & 9 \\
Newark, New Jersey (1 1) & $1981-85$ & 21 \\
Florida (24) & $1981-86$ & 9 \\
$\quad$ White (non-Hispanic) & & 2 \\
$\quad$ Hispanic & & 6 \\
$\quad$ Black (non-Haitian) & & 12 \\
$\quad$ Haitian & $1981-85$ & 27 \\
San Francisco, California (15) & $1980-82$ & 33 \\
Port-au-Prince, Haiti (7) & $1983-88$ & 24 \\
Rio de Janiero, Brazil (100) & - & 52 \\
Spain (26) & $1983-87$ & 67 \\
Madrid, Spain (25) & &
\end{tabular}

TABLE 2

Prevalence of HIV infection in patients with active fuberculosis

\begin{tabular}{lcc}
\hline Geographical source (reference) & Years & Seropositive (\%) \\
\hline Miami, Florida (30) & $1985-87$ & 31 \\
Brooklyn, New York (31) & $1987-88$ & 25 \\
San Francisco, California (33) & $1986-88$ & 28 \\
Kinshasa, Zaire (32) & $1985 / 87$ & 38 \\
Lusaka, Zambia (101) & 1985 & 24 \\
Lusaka, Zambia (102) & 1989 & 72 \\
Bujumbura, Burundi (103) & 1986 & 54 \\
Cité Soleil, Haiti (104) & 1989 & 39 \\
Haiti (rural) (105) & $1989-90$ & 24 \\
Rio de Janeiro, Brazil (106) & 1987 & 3 \\
Turkey (107) & $1983-87$ & 0 \\
\hline
\end{tabular}

Epidemiological understanding of $M$ avium complex infection in AIDS is incomplete. It is generally assumed, as in non-AIDS cases, that bacteria are acquired from environmental sources and that disease follows recent rather than remote infection $(17,20)$. It is uncertain, however, whether reactivation of latent infection might occur, and whether AIDS patients ever acquire $M$ avium complex from other infected humans. Because pathogenic $M$ avium can enter intestinal epithelial cells, and because of its anatomic predilection for the abdomen in AIDS, the upper gastrointestinal tract is believed to be a common portal of entry. The respiratory tract and possibly the rectum may also be initial sites of infection $(17,41)$.

The prevalence of disseminated $M$ avium complex among AIDS patients registered in the United States has been about $5 \%(20)$, but this is a gross underestimate due to incomplete diagnosis and 
reporting. When sought, the diagnosis can be made ante mortem in one-quarter or more, and post mortem in one-half of patients $(3,5,6,42)$. Disseminated $M$ avium complex arises late in the course of HIV disease, typically preceded by at least one other AIDS-defining condition (43). Since $M$ avium is less virulent than $M$ tuberculosis in humans, it is not surprising that an even greater degree of CD4+ cell depletion (usually less than $100 / \mathrm{mm}^{3}$, and often less than $50 / \mathrm{mm}^{3}$ ) is required before disseminated $M$ avium complex appears $(42,44-46)$.

\section{PATHOGENESIS}

Alveolar and tissue macrophages are the main effector cells against mycobacteria, which are primarily intracellular pathogens. The ability of mycobacteria to survive and multiply within macrophages is a key aspect of their virulence (47). Helper/inducer $\mathrm{T}$ cells are required to activate macrophages, thereby potentiating their antibacterial functions (48). In AIDS, deficient lymphokine support from CD4+ T cells could account for inadequate killing of mycobacteria by macrophages, impaired activation of cytolytic CD8+ T cells (49), and a blunted antibody response by B cells. Thus, the inexorable depletion of CD4+ lymphocytes in HIV-infected persons provides a clear - though not necessarily complete - explanation for their susceptibility to mycobacterial disease. Consistent with the critical role of $T$ helper cell deficiency are the findings that mononuclear phagocytes from AIDS patients function normally ex vivo when stimulated by normal Thelper cells (50), and that progression to disease occurs when circulating CD $4+\mathrm{T}$ cells decline to $400 / \mathrm{mm}^{3}$ or less.

However, since cells of the mononuclear phagocyte system are infected early in HIV disease (51), intrinsic functional defects in effector macrophages or in antigen-presenting cells, such as dendritic cells in lymph nodes, might contribute to the extraordinary success of mycobacteria in parasitizing AIDS patients. Investigations of macrophage function have yielded varied results depending upon the system studied $(51,52)$, and the importance of intrinsic defects in this component of the cellular immune response remains unsettled.

While AIDS clearly promotes mycobacterial disease, it is possible that the latter advances HIV infection as well. T cell activation in response to mycobacterial antigens might result in increased expression of HIV (53). Additionally, macrophages serve as repositories for HIV (51), and their migration and subsequent lysis during mycobacterial infection might disseminate virions capable of infecting fresh cells. Moreover, transient immuno- suppressive effects associated with mycobacterial disease may be added to those due to HIV (54).

DNA probes have identified over $90 \%$ of $M$ avium complex isolates from AIDS patients as $M$ avium (55). Although there is an excess proportion of certain serovars (eg, 4, 8 and 1), this varies geographically, and DNA probes have demonstrated genetic similarity among most pathogenic isolates (56). Virulent strains produce transparent colonies and often bear plasmids (57). The virulence factors associated with these findings remain unclear, but may pertain to adherence to and invasion of intestinal mucosal cells, or to the ability to abort bactericidal mechanisms within macrophages (58).

\section{CLINICAL PRESENTATION}

TB produces a major constitutional illness in AIDS patients despite their weakened cell-mediated immunity. Virtually all have fever, usually exceeding $39^{\circ} \mathrm{C}$. The spectrum of clinical and radiographic features reflects the degree of immunodeficiency, which roughly parallels the circulating CD4+ lymphocyte count. Localized lung disease predominates in patients who present 'early', as much as two to three years before fullblown AIDS. Tuberculin reactivity is preserved in over half of such patients $(30,33)$. With more advanced immunodeficiency, the infection is no longer contained locally: regional or disseminated lymphadenopathy, extrapulmonary foci and cutaneous anergy become characteristic. Lymphohematogenous dissemination is probably routine in patients with clinical AIDS, as indicated by the yield of blood culture $(25,37,59,60)$.

Even in the setting of AIDS, TB produces intrathoracic manifestations in the majority of patients $(21,30,33)$. When immunodeficiency is still moderate, one encounters the upper zone cavitary disease classically associated with reactivated TB, as reported in about one-quarter of cases from seroprevalence studies (30-33). With overt AIDS, lung opacities are noncavitary and often appear in segments atypical of adult TB (middle lobe and lingula, anterior segment of upper lobe, basal segments of lower lobes), sometimes resembling other bacterial pneumonias clinically and radiographically. Pleural effusions are at least as frequent as in non-AIDS patients $(15,16,30,37)$.

The hallmark of AIDS-related thoracic TB is the presence of hilar and/or mediastinal lymphadenopathy, usually asymmetric, accompanied or not by lung infiltrates. This pattern is associated with a low CD4 count (31) and recapitulates progressive primary infection as traditionally encountered in children and adolescents. The author and others have discovered endobronchial 
involvement (compression and/or erosion by lymph nodes, tuberculous bronchitis) not infrequently in such patients during diagnostic bronchoscopy (61). Intrathoracic lymph nodes may be the site of reactivation in some instances, leading to secondary tuberculous pneumonia by bronchogenic spread of bacilli. Others may represent recent primary infection, which could contribute to cases appearing 'late' in the course of AIDS, after the usual period of reactivation (15, 21,36).

Extrathoracic TB with or without intrathoracic disease has been detected in two-thirds or more of patients with overt AIDS (9,11-15,21) and in onehalf of those identified in seroprevalence studies $(30,31,33)$. TB can appear at virtually any site and must be considered in the differential diagnosis of lymphadenopathy (cervical, abdominal, axillary, inguinal and sometimes multifocal), brain mass (62), meningitis, soft tissue abscess of the anterior chest wall (63) and elsewhere, genitourinary lesions, serositis, pancreatitis and a variety of unusual foci $(11,21,37)$. Careful diagnostic search (eg, by computed tomography and thorough culturing) often reveals multifocal disease.

Overt miliary dissemination is found in $10 \%$ or more of cases $(11,31,37)$, and cryptic miliary lesions are probably much more frequent. Overwhelming miliary TB can produce a syndrome resembling septic shock with multisystem organ failure (64). Patients lacking a miliary pattern on chest roentgenogram are at particular risk of dying before the TB is recognized or treated empirically.

$M$ avium complex infection is more indolent and insidious than TB in its clinical presentation. Constitutional illness (fever, malaise, anorexia, wasting, anemia) predominates over localized symptoms such as diarrhea, abdominal pain or cough (1-6,42). Whereas overt focal lesions are present in most patients with HIV-related TB, the physical examination and chest roentgenogram are typically unrevealing in disseminated $M$ avium complex, disclosing only stigmata of AIDS or focal lesions due to another cause. It may be difficult to attribute clinical findings to $M$ avium complex, given their nonspecific nature and the confounding presence of one or more other late complications of AIDS. Indeed, $M$ avium complex often goes undiagnosed during life, only to be found at autopsy $(6,20)$.

Several localized syndromes caused by $M$ avium complex have been described. Abdominal findings are most common and take several forms: lymphadenopathy, intestinal infiltration with diarrhea, hepatomegaly and splenomegaly $(2,5,65)$. Enlarged lymph nodes can cause extrahepatic biliary obstruction $(4,5)$. The intestinal involvement can produce a malabsorption syndrome which resembles Whipple's disease clinically and histologically, except that the mucosal macrophages are packed with acid-fast bacilli $(5,65,66)$. Other syndromes include pericarditis (67), granulomatous hepatitis (2), suppurative lymphadenitis in patients receiving zidovudine (68), and endophthalmitis.

Whereas $M$ avium complex disease usually resembles pulmonary TB in patients without AIDS, clinically obvious lung involvement is rare in those with AIDS, even when $M$ avium complex can be cultured from respiratory secretions, and despite microscopic involvement of the lungs at autopsy (1). Radiographic opacities have been described in some series without pathological confirmation $(16,69)$; in the author's experience coexisting disease usually accounts for the radiographic lesions, an impression supported by autopsy findings $(6,70,71)$. A well documented though infrequent intrathoracic manifestation is lymphadenopathy (69), sometimes associated with endobronchial masses (72). Thus $M$ avium complex resembles cytomegalovirus, a common copathogen, in that it is often isolated from respiratory secretions of AIDS patients without causing apparent disease.

\section{PATHOLOGY}

AIDS patients are generally considered to have a deficient granulomatous response due to the profound impairment of helper T cell function (50). A spectrum of histological findings has been reported in TB, ranging from well formed epithelioid granulomas to a lack of typical granulomas (10$13,21,73-76)$, and probably reflecting the variable degree of immunodeficiency. In the author's experience tuberculous lesions nearly always contain recognizable granulomatous inflammation when biopsied, even in disseminated TB (37). Granulomas are often poorly formed, however, especially in patients with overt AIDS. Necrosis is present in the majority of biopsies and is usually extensive in lymph nodes $(37,77)$. Infrequently, acid-fast bacilli are present in lesions showing only nonspecific inflammation, emphasizing the need to perform appropriate stains for bacteria and fungi even when the expected histological abnormalities are absent (21). In some instances a positive biopsy culture without histological evidence of TB may reflect the inclusion of bacilli circulating in blood or lymph (11).

A different pathological picture occurs in patients dying from overwhelming miliary TB (37). Lesions are dominated by extensive granular necrosis with nuclear debris and numerous acid- 
fast bacilli; epithelioid cells and lymphocytes are sparse or absent. This striking pattern closely resembles the 'nonreactive' TB described in decades past, often with underlying hematological disease (78). The poor cellular response in such patients probably reflects the immunocompromise of AIDS, although one cannot exclude overriding suppressor activity induced by TB itself $(54,79,80)$. The pathogenesis of such extensive necrosis despite a paucity of viable inflammatory cells might involve direct toxicity of $M$ tuberculosis for macrophages $(47,81)$ or unbridled cytolytic T cell activity (49)

The histological features of $M$ avium complex infection differ considerably from those of TB in AIDS patients, although a spectrum exists for both pathogens. Tuberculous lesions more closely resemble classical epithelioid granulomas, display much greater tissue necrosis, and often have an associated lymphocytic infiltrate. In $M$ avium complex infection, granulomas occur in one-half or fewer cases, and are usually non-necrotizing and poorly formed $(11,73)$. Discrete granulomas are probably more common in ante mortem biopsies than at autopsy, and tend to be better formed in some organs (eg, liver) $(76,82)$ than in others (eg, lung), as noted in non-AIDS patients (83). More often, however, the host reaction consists of foamy, granular or striated histiocytes (pseudoGaucher cells) disposed singly, in clusters, or diffusely and packed with 'globi' of acid-fast bacilli $(1,71,73,75,82,84,85)$. This histological pattern, likened to that of lepromatous leprosy (4), has not been described in TB. The blander and less destructive inflammatory response in disseminated $M$ avium complex corresponds to the milder clinical illness.

\section{DIAGNOSIS}

Mycobacterial diseases rank among the most frequent and important complications of AIDS. Given their protean manifestations, they should be considered in any patient with known or suspected HIV infection and unexplained fever and constitutional symptoms, with or without obvious focal lesions. The diagnosis is more easily overlooked in AIDS than in non-AIDS patients (86), in part because of the higher frequency of atypical, extrapulmonary and 'cryptic' disseminated presentations. The differential diagnosis must be tailored to the patient's personal history and geographic background, but includes other bacterial infections (pneumonia, salmonellosis, endocarditis), fungal infections (cryptococcosis, histoplasmosis, coccidioidomycosis), parasitic infections (cerebral toxoplasmosis, visceral leishmaniasis), pulmonary and extrapulmonary pneumocystosis, viruses (cytomegalovirus), and neoplasms (lymphoma, Kaposi's sarcoma). All diagnostic specimens from such patients should be cultured and stained for acid-fast bacilli using appropriate techniques, even (in the case of biopsies) when the histological features do not suggest granulomatous inflammation.

Diagnostic techniques for TB are applied in the usual manner but, given the high frequency of dissemination, the author recommends routine culturing of lower respiratory tract specimens, urine and blood, supplemented by cerebrospinal fluid, lymph node or abscess aspirate, serosal fluid, stool or tissue biopsy as indicated $(37,59,60)$. For example, the present author recently diagnosed TB from the culture of a brain biopsy which revealed only toxoplasmosis histologically. Occasional patients have positive sputum cultures in the absence of radiographic lung infiltrates; this may reflect an attenuated inflammatory response in lung parenchyma or an endobronchial or even an upper airway (eg, laryn geal) source of bacilli. A thorough attempt at early diagnosis by appropriately stained smears or his topathology is advisable, since the severity of ill ness and the alternative diagnoses make empiric therapy while awaiting cultures risky in this population.

The diagnosis of $M$ avium complex infection from sputum or other noninvasive sampling is complicated by the possibility of colonization. In deed, given the relatively weak host response to $M$ avium complex in AIDS, the clinical distinction between colonization and invasive disease is often unclear in individual patients. Initially, $M$ avium may be cultured unexpectedly from sputum, bronchoscopic specimens or stool, without as sociated clinical findings (42). In AIDS patients, such apparent colonization (or early infection) often heralds disseminated infection in the months to come $(5,86)$. If clinical evidence of dis ease is present, blood culture gives simple and efficient proof of disseminated $M$ avium complex, obviating tissue biopsy (liver, bone marrow, lymph node, duodenal mucosa), except when the severity of illness dictates rapid diagnosis. Two blood specimens suffice for high sensitivity (87). A presumptive diagnosis of invasive infection may be made if $M$ avium is cultured from two or more superficial sites (sputum, stool, urine) in a febrile patient.

AIDS has prompted renewed interest in the cultivation of blood for diagnosis of mycobacterial infections. Sensitivity is enhanced by the cell lysis/centrifugation method, using a commercial system (Dupont Isolator) (88) or sterile water (59) to release bacilli from leukocytes. Blood can also 
be cultured directly in the Bactec radiometric system (Johnston Laboratories, Maryland), which modestly shortens the delay to detection of growth $(59,88)$.

\section{MANAGEMENT}

For initial chemotherapy of TB, standard regimens for pulmonary disease (89) are appropriate and do not require modification because of extrapulmonary dissemination. The currently recommended regimen comprises isoniazid, rifampin and pyrazinamide for the first two months; however, the addition of ethambutol is advisable in many centres because of a high frequency (greater than $10 \%$ ) of primary resistance to isoniazid, as well as increasing resistance to rifampin. While the resolution of constitutional symptoms, lung opacities and lymphadenopathy may seem slow in occasional patients, there is no documentation that the average time course of response is less favorable than in non-AIDs patients. The time course of sputum conversion is not greatly different than in non-HIV patients $(12,32,33,90)$, though in one controlled trial a higher proportion of HIV seropositive patients (10\% versus $2 \%$ ) still had positive cultures after a six month regimen (91).

An increased frequency of adverse reactions to medications has been reported in HIV-infected patients, though not in all series $(15,33,90,92)$. Skin reactions may be more common, especially to thiacetazone, but significant hepatotoxicity does not appear to be increased $(15,30,32,33,91)$.

Early failure despite appropriate treatment has been suggested in a few cases $(11,93)$ but is difficult to assess because of uncertain compliance and concomitant disease, and because clinical progression during adequate therapy (particularly of central nervous system lesions) is well described in immunocompetent patients.

The optimal duration of therapy is unestablished. The standard six month regimen controls TB in most patients but may not achieve adequate lifelong protection against relapse $(91,93,94)$. Thus, treatment is currently recommended for at least nine months, and for at least six months beyond culture negativity (29). The relapse rate in patients who have completed therapy may be higher than in non-HIV patients, but appears to be less than $10 \%$ based on limited data $(90,92)$. Lifelong secondary prevention using isoniazid has been advocated by some, but the author believes that clinical follow-up is sufficient pending further data.

The great majority of TB patients achieve clinical and bacteriological cure if they adhere to therapy. While mortality is high during the one to two years after diagnosis, most deaths are attributable to other complications of AIDS $(11,12,15,32,91)$. The overall mortality from TB, including patients who succumb before or shortly after initiation of therapy, exceeds 10\% (95). The high proportion of disseminated disease (fatal in $25 \%$ of the author's cases) (37) contributes to the poor outcome. Death rates in the remaining patients are less than $10 \%$ but may be higher than in non-HIV cases $(11,12,15,30,31,33,91)$.

Given their susceptibility to TB, HIV-infected persons are a key target for preventive measures. Identification of latent infection commands high priority in their management, but is clouded by the progressive loss of dermal reactivity as immunodeficiency worsens. All individuals at risk for HIV infection should undergo skin testing as early as possible; a $5 \mathrm{~mm}$ reaction to purified protein derivative of tuberculin (5 tuberculin units) is taken as positive in this setting (29) and mandates preventive chemotherapy regardless of age. Patients who already have clinical AIDS are usually anergic $(11,15,21,24,31,37)$; empiric preventive therapy is a reasonable option in those who come from populations with a high (greater than 50\%) likelihood of latent infection.

While outcome trials on chemoprevention are lacking in HIV patients, some observations suggest that isoniazid is efficacious (34). The recommended duration is 12 , not six, months (29). A goal of current research is the development of brief (less than six months) regimens involving two to three drugs (eg, rifampin and pyrazinamide), which should improve the practicability and net efficacy of chemoprevention.

The use of BCG vaccine in the HIV-infected patient is controversial. Local reactions, regional lymphadenitis and disseminated infection are possible complications in the immunocompromised patient. BCG may be given to asymptomatic children in regions at high risk of $\mathrm{TB}$, but should be avoided in anyone with clinical signs of HIV disease (96).

Whereas TB is perhaps the most gratifying AIDSrelated opportunistic infection to treat, disseminated $M$ avium complex remains a frustrating therapeutic problem. Most isolates show resistance to first-line anti-TB drugs $(5,42,87,97)$; pyrazinamide is less easily tested but lacks efficacy in vitro (98). Clofazimine and rifabutin (ansamycin) have activity in vitro but have been disappointing alone or with other agents against disseminated $M$ avium complex $(4,5,97)$. Other drugs which often show activity include amikacin, ciprofloxacin, ethambutol, ethionamide and cycloserine. While some data support the relevance of sensitivity testing to clinical efficacy in non-AIDS 
patients, a correlation has not yet been shown in AIDS $(42,43)$.

It is generally agreed that $M$ avium complex can cause important systemic illness, sometimes with localized organ dysfunction, thus mandating therapy. However its contribution to morbidity and mortality in the setting of advanced AIDS can be difficult to discern. The great majority of patients with disseminated $M$ avium complex die within a year of diagnosis, but tissue injury and death are due mainly to other diseases $(5,6,42,70)$. Conversely, patients have survived for over a year with untreated disseminated $M$ avium complex (99). It remains uncertain whether disseminated $M$ avium complex decreases survival relative to that of comparably immunodepressed but uninfected AIDS patients $(17,20,86)$.

Multidrug regimens have been employed based on pre-AIDS experience and possible synergism, but there have been no controlled trials comparing regimens or, indeed, demonstrating symptomatic or survival benefit from antimicrobial treatment. Initial experience with rifabutin, clofazimine and other agents proved disappointing. Bacteremia usually persisted, sometimes undiminished in quantity $(4,5,97)$. Although some patients showed

\section{REFERENCES}

1. Zakowski P, Fligiel S, Berlin GW, Johnson BL. Disseminated Mycobacterium avium-intracellulare infection in homosexual men dying of acquired immunodeficiency. JAMA 1982;248:2980-2.

2. Greene JB, Sidhu GS, Lewin S, et al. Mycobacterium avium-intracellulare: A cause of disseminated life-threatening infection in homosexuals and drug abusers. Ann Intern Med 1982;97:539-46.

3. Macher AM, Kovacs JA, Gill V, et al. Bacteremia due to Mycobacterium avium-intracellulare in the acquired immunodeficiency syndrome. Ann Intern Med 1983;99:782-5.

4. Wong B, Edwards FF, Kiehn TE, et al. Continuous high-grade Mycobacterium avium-intracellulare bacteremia in patients with the acquired immune deficiency syndrome. Am J Med 1985;78:35-40.

5. Hawkins CC, Gold JWM, Whimbey E, et al. Mycobacterium avium complex infections in patients with the acquired immunodeficiency syndrome. Ann Intern Med 1986;105:184-8.

6. Wallace JM, Hannah JB. Mycobacterium avium complex infection in patients with the acquired immunodeficiency syndrome. Chest 1988;93:926-32.

7. Pape JW, Liautaud B, Thomas F, et al. Characteristics of the acquired immunodeficiency (AIDS) in Haiti. N Engl J Med 1983;309:945-50.

8. Vieira J, Frank E, Spira TJ, Landesman SH. Acquired immune deficiency in Haitians. N Engl J Med 1983;308:125-9.

9. Pitchenik AE, Cole C, Russell BW, Fischl MA, Spira TJ, Snider DE. Tuberculosis, atypical tuberculosis, and the acquired immunodeficiency symptomatic responses (86), most did not. Exte sive tissue infection has been found at autops even after prolonged treatment $(4-6,97)$. Noneth less, there are recent reports of clinical succe $(42,43,46,86)$, notably in an Australian series which a higher dose of rifabutin was employed ( 4 and in an American series in which amikacin a ciprofloxacin were administered (46).

The decision to treat disseminated $M$ avi complex depends upon the presence of significa clinical findings, exclusion of other (more tre able) causes, and the patient's motivation a ability to follow a complex and potentially to regimen (43). At present the goal of therapy control of symptoms, not bacteriologic cure $6,46,86,97)$. An empiric regimen might inclu three to five of the following: amikacin, etha butol, rifampin (or rifabutin or rifapenten ciprofloxacin, clofazimine or isoniazid $(17,43,4$ When unidentified acid-fast bacilli are countered in a clinical specimen, the init regimen must also be adequate for $M$ tuberculos pending speciation. An appropriate alternative some patients, once TB has been excluded, is simply suppress symptoms with a nonsteroic anti-inflammatory agent.

syndrome among Haitian and non-Haitian patien in south Florida. Ann Intern Med 1984;101:641-

10. Pitchenik AE, Rubinson HA. The radiographic appearance of tuberculosis in patients with the acquired immune deficiency syndrome (AIDS) and pre-AIDS. Am Rev Respir Dis 1985;131:393-6.

11. Sunderam G, McDonald RJ, Maniatis T, Oleske Kapila R, Reichman LB. Tuberculosis as a manifestation of the acquired immunodeficiency syndrome (AIDS). JAMA 1986;256:362-6.

12. Louie E, Rice LB, Holzman RS. Tuberculosis in non-Haitian patients with acquired immunodeficiency syndrome. Chest 1986;90:542

13. Duncanson FP, Hewlett D Jr, Maayan S, et al. Mycobacterium tuberculosis infection in the acquired immunodeficiency syndrome: A review 14 patients. Tubercle 1986;67:295-302.

14. Handwerger S, Mildvan D, Senie R, McKinley FW Tuberculosis and the acquired immunodeficiency syndrome at a New York City hospital: 1978-198 Chest 1987;91:176-80.

15. Chaisson RE, Schecter GF, Theuer CP, Rutherfor GW, Echenberg DF, Hopewell PC. Tuberculosis i patients with the acquired immunodeficiency syndrome. Am Rev Respir Dis 1987;136:570-4.

16. Modilevsky T, Sattler FR, Barnes PF.

Mycobacterial disease in patients with human immunodeficiency virus infection. Arch Intern M 1989;149:2201-5.

17. MacDonell KB, Glassroth J. Mycobacterium aviun complex and other nontuberculous mycobacteria in patients with HIV infection. Semin Respir Infe 1989;4:123-32.

18. Levine B, Chaisson RE. Mycobacterium kansasii causing chronic cavitary pulmonary disease in $\mathrm{Al}$ 
patients which is responsive to antituberculous therapy. Am Rev Respir Dis 1990;141:A612. (Presented at World Conference on Lung Health, Boston, May 20-24, 1990)

19. Sherer R, Sable R, Sonnenberg M, et al. Disseminated infection with Mycobacterium kansasii in the acquired immunodeficiency syndrome. Ann Intern Med 1986;105:710-2.

20. Horsburgh CR, Selik RM. The epidemiology of disseminated nontuberculous mycobacterial infection in the acquired immunodeficiency syndrome (AIDS). Am Rev Respir Dis 1989;139:4-7.

21. Pitchenik AE, Fertel D, Bloch AB. Mycobacterial disease: Epidemiology, diagnosis, treatment, and prevention. Clin Chest Med 1988;9:425-41.

22. Murray JF. The white plague: Down and out, or up and coming? Am Rev Respir Dis 1989;140:1788-95.

23. Harries AD. Tuberculosis and human immunodeficiency virus infection in developing countries. Lancet 1990;i:387-90.

24. Rieder HL, Cauthen GM, Bloch AB, et al. Tuberculosis and acquired immunodeficiency syndrome - Florida. Arch Intern Med 1989; 149:1268-73.

25. Bouza E, Martin-Scapa C, Bernaldo de Quiros JCL, et al. High prevalence of tuberculosis in AIDS patients in Spain. Eur J Clin Microbiol Infect Dis 1988;7:785-8.

26 March-Ayuela P de. Choosing an appropriate criterion for true or false conversion in serial tuberculin testing. Am Rev Respir Dis 1990;141:815-20.

27. Okello DO, Sewankambo N, Goodgame R, et al. Absence of bacteremia with Mycobacterium avium-intracellulare in Ugandan patients with AIDS. J Infect Dis 1990;162:208-10.

28. Centers for Disease Control. Revision of the CDC surveillance case definition for acquired immunodeficiency syndrome. MMWR 1987;36: 1S-15S.

29. Centers for Disease Control. Tuberculosis and human immunodeficiency virus infection: Recommendations of the advisory committee for elimination of tuberculosis. MMWR 1989;38:236-50.

30. Pitchenik AE, Burr J, Suarez M, Fertel D, Gonzalez G, Moas C. Human T-cell lymphotropic virus-III (HTLV-III) seropositivity and related disease among 71 consecutive patients in whom tuberculosis was diagnosed. Am Rev Respir Dis $1987 ; 135: 875-9$.

31. Shafer RW, Chirgwin KD, Glatt AE, Dahdouh MA, Landesman SH, Susster B. HIV prevalence of immunosuppression and drug resistance in patients with tuberculosis in an area endemic for AIDS. Presented at the Vth International Conference on AIDS, Montreal, June 1989:ThBP50. AIDS. (In press) (Abst)

32. Colebunders RL, Ryder RW, Nzilambi N, et al. HIV infection in patients with tuberculosis in Kinshasa, Zaire. Am Rev Respir Dis 1989; 139:1082-5.

33. Theuer CP, Hopewell PC, Elias D, Schecter GF, Rutherford GW, Chaisson RE. Human immunodeficiency virus infection in tuberculosis patients. J Infect Dis 1990;162:8-12.

34. Selwyn PA, Hartel D, Lewis VA, et al. A prospective study of the risk of tuberculosis among intravenous drug users with human immunodeficiency virus infection. N Engl J Med 1989;320:545-50.

35. Bloch AB, Rieder HL, Kelly GD, Cauthen GM, Hayden CH, Snider DE. The epidemiology of tuberculosis in the United States. Semin Respir Infect 1989;4:157-70.

36. Centers for Disease Control. Tuberculosis and acquired immunodeficiency syndrome - New York City. MMWR 1987;36:785-95.

37. Kramer F, Modilevsky T, Waliany AR, Leedom JM, Barnes PF. Delayed diagnosis of tuberculosis in patients with human immunodefiency virus infection. Am J Med 1990;89:451-6.

38. Raufman J-P. Odynophagia/dysphagia in AIDS. Gastroenterol Clin North Am 1988;17:599-614.

39. Perri G di, Cruciani M, Danzi MC, et al. Nosocomial epidemic of active tuberculosis among HIV-infected patients. Lancet 1989;ii:1502-4.

40. Klein NC, Duncanson FP, Lenox TH, Pitta A, Cohen SC, Wormser GP. Use of mycobacterial smears in the diagnosis of pulmonary tuberculosis in AIDS/ARC patients. Chest 1989;95:1190-2.

41. Damsker B, Bottone EJ. Mycobacterium avium-Mycobacterium intracellulare from the intestinal tracts of patients with the acquired immunodeficiency syndrome: Concepts regarding acquisition and pathogenesis. J Infect Dis 1985;151:179-80.

42. Hoy J, Mijch A, Sandland LM, Grayson L, Lucas R, Dwyer B. Quadruple-drug therapy for Mycobacterium avium-intracellulare bacteremia in AIDS patients. J Infect Dis 1990;161:801-5.

43. Inderlied CB, Young LS. Disseminated Mycobacterium avium complex infection. In: Volberding P, Jacobson MA, eds. AIDS Clinical Review 1990. New York: Marcel Dekker, 1990: 165-91.

44. Masur H, Ognibene FP, Yarchoan R, et al. CD4 counts as predictors of opportunistic pneumonias in human immunodeficiency virus (HIV) infection. Ann Intern Med 1989;111:223-31.

45. Murray HW, Scavuzzo DA, Chaparas SD, Roberts RB. T lymphocyte responses to mycobacterial antigen in AIDS patients with disseminated Mycobacterium avium-Mycobacterium intracellulare infection. Chest 1988;93:922-5.

46. Chiu J, Nussbaum J, Bozzette S, et al. Treatment of disseminated Mycobacterium avium complex infection in AIDS with amikacin, ethambutol, rifampin, and ciprofloxacin. Ann Intern Med $1990 ; 113: 358-61$.

47. Crowle AJ. The tubercle bacillus-human macrophage relationship studied in vitro. In: Bendinelli M, Friedman H, eds. Mycobacterium tuberculosis: Interactions with the Immune System. New York: Plenum Press, 1988:99-135.

48. Dannenberg AM. Immune mechanisms in the pathogenesis of pulmonary tuberculosis. Rev Infect Dis 1989;11:S369-78.

49. Kaufmann SHE. In vitro analysis of the cellular mechanisms involved in immunity to tuberculosis. Rev Infect Dis 1989;11:S448-54.

50. Murray HW. Macrophage activation in the acquired immunodeficiency syndrome. Adv Exp Med Biol 1988;239:297-307.

51. Meltzer MS, Skillman DR, Gomatos PJ, Kalter DC, Gendleman HE. Role of mononuclear phagocytes in the pathogenesis of human immunodeficiency 
virus infection. Annu Rev Immunol 1990;8:169-94.

52. Beck JM, Shellito J. Effects of human immunodeficiency virus on pulmonary host defenses. Semin Respir Infect 1989;4:75-84.

53. Zagury D, Bernard J, Leonard R, et al. Long-term cultures of HTLV-III-infected T cells: A model of cytopathology of T-cell depletion in AIDS. Science 1986;231:850-3.

54. Ellner JJ, Wallis RS. Immunologic aspects of mycobacterial infections. Rev Infect Dis 1989;11:S455-9.

55. Guthertz LS, Damsker B, Bottone EJ, et al. Mycobacterium avium and Mycobacterium intracellulare infections in patients with and without AIDS. J Infect Dis 1989; 160:1037-41.

56. Hampson SJ, Portaels E, Thompson J, et al. DNA probes demonstrate a single highly conserved strain of Mycobacterium avium infecting AIDS patients. Lancet 1989;i:65-8,

57. Gangadharam PRJ, Perumal VK, Jairam BT, Podapati NR, Taylor RB, LaBrecque JF. Virulence of Mycobacterium avium complex strains from acquired immune deficiency syndrome patients: Relationship with characteristics of the parasite and host. Microbial Pathogenesis 1989;7:263-78.

58. Frehel C, Chastellier C de, Lang T, Rastogi N. Evidence for inhibition of fusion of lysosomal and prelysosomal compartments with phagosomes in macrophages infected with pathogenic Mycobacterium avium. Infect Immun 1986;52:252-62.

59. Shafer RW, Goldberg R, Sierra M, Glatt AE. Frequency of Mycobacterium tuberculosis bacteremia in patients with tuberculosis in an area endemic for AIDS. Am Rev Respir Dis 1989;140:1611-3.

60. Barber TW, Craven DE, McCabe WR. Bacteremia due to Mycobacterium tuberculosis in patients with human immunodeficiency virus infection. Medicine 1990;69:375-83.

61. Wasser LS, Shaw GW, Talavera W. Endobronchial tuberculosis in the acquired immunodeficiency syndrome. Chest 1988;94:1240-4.

62. Bishburg E, Sunderam G, Reichman LB, Kapila R. Central nervous system tuberculosis with the acquired immunodeficiency syndrome and its related complex. Ann Intern Med 1986;105:210-3.

63. Rasheed Q, Hill AR, Suster B. Tuberculosis presenting as chest wall abscess. Am Rev Respir Dis 1990;141:A443. (Presented at World Conference on Lung Health, Boston, May 20-24, 1990)

64. Ahuja SS, Ahuja SK, Thelmo W, Phelps KR, Hill R. Hemodynamic confirmation of septic shock complicating miliary tuberculosis. Am Rev Respir Dis 1990;141:A140. (Presented at World Conference on Lung Health, Boston, May 20-24, 1990)

65. Gray JR, Rabeneck L. Atypical mycobacterial infection of the gastrointestinal tract in AIDS patients. Am J Gastroenterol 1989;84:1521-4.

66. Gillin JS, Urmacher C, West R, Shike M. Disseminated Mycobacterium avium-intracellulare infection in acquired immunodeficiency syndrome mimicking Whipple's disease. Gastroenterology 1983;85:1187-91.

67. Woods GL, Goldsmith JC. Fatal pericarditis due to Mycobacterium avium-intracellulare in acquired immunodeficiency syndrome. Chest 1989;95: 1355-7.

68. Barbaro DJ, Orcutt VL, Coldiron BM. Mycobacterium avium-Mycobacterium intracellulare infection limited to the skin and lymph nodes in patients with AIDS. Rev Infect Dis 1989; 11:625-8.

69. Marinelli DL, Albelda SM, Williams TM, Kern JA, Iozzo RV, Miller WT. Nontuberculous mycobacterial infection in AIDS: Clinical, pathologic, and radiographic features. Radiology 1986; 160:77-82.

70. Ruf B, Schuermann D, Brehmer W, Pohle HD. Pulmonary manifestations due to Mycobacterium avium-Mycobacterium intracellulare in AIDS patients. Am Rev Respir Dis 1990;141:A611. (Presented at World Conference on Lung Health, Boston, May 20-24, 1990)

71. Nash G, Fligiel S. Pathologic features of the lung in the acquired immune deficiency syndrome (AIDS): An autopsy study of seventeen homosexual males. Am J Clin Pathol 1984;81:6-12.

72. Packer SJ, Cesario T, Williams JH. Mycobacterium avium complex infection presenting as endobronchial lesions in immunosuppressed patients. Ann Intern Med 1988;109:389-93.

73. Harawi SJ. The microorganisms. In: Harawi SJ, O'Hara CJ, eds. Pathology and Pathophysiology of AIDS and HIV-related Diseases. St Louis: CV Mosby, 1989:57-81.

74. Jagadha V, Andavolu RH, Huang CT. Granulomatous inflammation in the acquired immune deficiency syndrome. Am J Clin Pathol 1985:84:598-602.

75. Klatt EC, Jensen DF, Meyer PR. Pathology of Mycobacterium avium-intracellulare infection in acquired immunodeficiency syndrome. Hum Pathol 1987; 18:709-14.

76. Orenstein MS, Tavitian A, Yonk B, et al. Granulomatous involvement of the liver in patients with AIDS. Gut 1985;26:1220-5.

77. Nambuya A, Sewankambo N, Mugerwa J, Goodgame R, Lucas S. Tuberculous lymphadenitis associated with human immunodeficiency virus (HIV) in Uganda. J Clin Pathol 1988;41:93-6.

78. O'Brien JR. Non-reactive tuberculosis. J Clin Pathol 1954;7:216-25.

79. Nakamura RM, Tokunaga T. Suppressor cells in mycobacterial infections. In: Bendinelli M, Friedman H, eds. Mycobacterium tuberculosis: Interactions with the Immune System. New York: Plenum Press, 1988:227-41.

80. Ellner JJ. Immunoregulatory function of mononuclear phagocytes in tuberculosis. In: Bendinelli M, Friedman H, eds. Mycobacterium tuberculosis: Interactions with the Immune System. New York: Plenum Press, 1988:243-62.

81. Myrvik QN, Leake ES, Goren MB. Mechanisms of toxicity of tubercle bacilli for macrophages. In: Bendinelli M, Friedman H, eds. Mycobacterium tuberculosis: Interactions with the Immune System. New York: Plenum Press, 1988:305-25.

82. Glasgow BJ, Anders K, Layfield LJ, Steinsapir KD, Gitnick GL, Lewin KJ. Clinical and pathologic findings in the liver in acquired immune deficiency syndrome (AIDS). Am J Clin Pathol 1985;83:582-8.

83. Farhi DC, Mason UG, Horsburgh CR Jr. Pathologic findings in disseminated Mycobacterium 
avium-intracellulare infection. Am J Clin Pathol 1986;85:67-72.

84. Chester AC, Winn WC Jr. Unusual and newly recognized patterns of nontuberculous mycobacterial infection with emphasis on the immunocompromised host. Pathol Annu 1986;21:251-70.

85. Solis OG, Belmonte AH, Ramaswamy G, Tchertkoff V. Pseudogaucher cells in Mycobacterium avium-intracellulare infections in acquired immune deficiency syndrome (AIDS). Am J Clin Pathol 1986;85:233-5.

86. Agins BD, Berman DS, Spicehandler D, El-Sadr W, Simberkoff MS, Rahal JJ. Effect of combined therapy with ansamycin, clofazimine, ethambutol, and isoniazid for Mycobacterium avium infection in patients with AIDS. J Infect Dis 1989; 159:784-7

87. Barnes PF, Arevalo C. Blood culture positivity patterns in bacteremia due to Mycobacterium avium-intracellulare. South Med J 1988;81:1059-60.

88. Kiehn TE, Cammarata R. Comparative recoveries of Mycobacterium avium-M intracellulare from Isolator lysis-centrifugaton and Bactec 13A blood culture systems. J Clin Microbiol 1988;26:760-1.

89. Perez-Stable EJ, Hopewell PC. Current tuberculosis treatment regimens: Choosing the right one for your patient. Clin Chest Med 1989;10:323-39.

90. Small PM, Schecter GF, Sande MA, Hopewell PC. Response to tuberculosis therapy in patients with AIDS. Program of 29th Interscience Conference on Antimicrobial Agents and Chemotherapy, 1989. (Abst 1066)

91. Mukadi Y, Perriens J, Williame JC, et al. Short course antituberculous therapy for pulmonary tuberculosis in HIV seropositive patients: A prospective controlled study. Am Rev Respir Dis 1990; 141:A266. (Presented at World Conference on Lung Health, Boston, May 20-24, 1990)

92. Perrone C, Ghoubontni A, Leport C, Salmon D, Bricaire F, Vilde JL. Tuberculosis in $60 \mathrm{HIV}$ infected patients. Program of 29th Interscience Conference on Antimicrubial Agents and Chemotherapy, 1989. (Abst 383)

93. Sunderam G, Mangura BT, Lombardo JM, Reichman LB. Failure of 'optimal' four-drug short-course tuberculosis chemotherapy in a compliant patient with human immunodeficiency virus. Am Rev Respir Dis 1987;136:1475-8.

94. Shafer RW, Jones WD. Relapse of tuberculosis in a patient with the acquired immunodeficiency syndrome despite twelve months of antituberculous therapy and continuation of isoniazid. Tubercle. (In press)

95. Walker AT, O'Brien RJ. Retrospective survey of treatment of tuberculosis in persons with AIDS. Am
Rev Respir Dis 1990;141:A268. (Presented at World Conference on Lung Health, Boston, May 20-24, 1990)

96. Quinn TC. Interactions of the human immunodeficiency virus and tuberculosis and the implications for BCG vaccination. Rev Infect Dis 1989;1 1:S379-84.

97. Masur H, Tuazon C, Gill V, et al. Effect of combined clofazimine and ansamycin therapy on Mycobacterium avium-Mycobacterium intracellulare bacteremia in patients with AIDS. J Infect Dis 1987; 155:127-9.

98. Heifets LB, Iseman MD, Crowle AJ, Lindholm-Levy PJ. Pyrazinamide is not active in vitro against Mycobacterium avium complex. Am Rev Respir Dis 1986; 134:1287-8.

99. Boldt K, Chomyc S, Miedzinski L, Taylor G, Evans GA. The clinical impact of mycobacterial infections in HIV infected persons. Presented at Vth International Conference on AIDS, Montreal, June 1989. (Abst ThBP67)

100. Kritski AL, Matida A, Galvao-Castro B. Tuberculosis and AIDS Rio de Janiero, Brazil: 1983-1988. Vth International Conference on AIDS, 1989. (Abst ThBP74)

101. Melbye M, Bayley A, Manuwele JK, et al. Evidence for heterosexual transmission and clinical manifestations of human immunodefiency virus infection and related conditions in Lusaka, Zambia. Lancet 1986;ii:1113-5.

102. Elliott A. Luo N, Tembo G, et al. The impact of human immunodeficiency virus on tuberculosis in Zambia: Preliminary report of a cohort study. Am Rev Respir Dis 1990;141:A260. (Presented at World Conference on Lung Health, Boston, May 20-24, 1990)

103. Standaert B, Niragira F, Kalende P, Piot P. The association of tuberculosis and HIV infection in Burundi. AIDS Res Hum Retroviruses 1989;5:247-51.

104. Clermont HC, Boulos R, Halsey NA, Brutus JR, Ruff AJ, Chaisson RE. HIV in adults with tuberculosis in Cite Soleil, Haiti. Am Rev Respir Dis 1990;141:A264. (Presented at World Conference on Lung Health, Boston, May 20-24, 1990)

105. Long R, Scalcini M, Manfreda M, et al. Impact of the human immunodeficiency virus type 1 on tuberculosis in rural Haiti. Am Rev Respir Dis 1991;143:69-73.

106. Kritski AL, Werneck EB, Gadelha MEC, et al. Association between active pulmonary tuberculosis and human immunodeficiency virus in Rio de Janiero, Brazil. IVth International Conference on AIDS, 1988. (Abst 5561)

107. Yenen OS, Ekinci E, Aydilek R, Baydar I. HIV infection and tuberculosis in Turkey. Chest 1988;94:674 


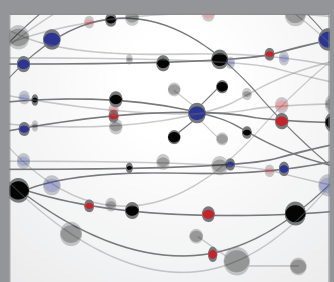

The Scientific World Journal
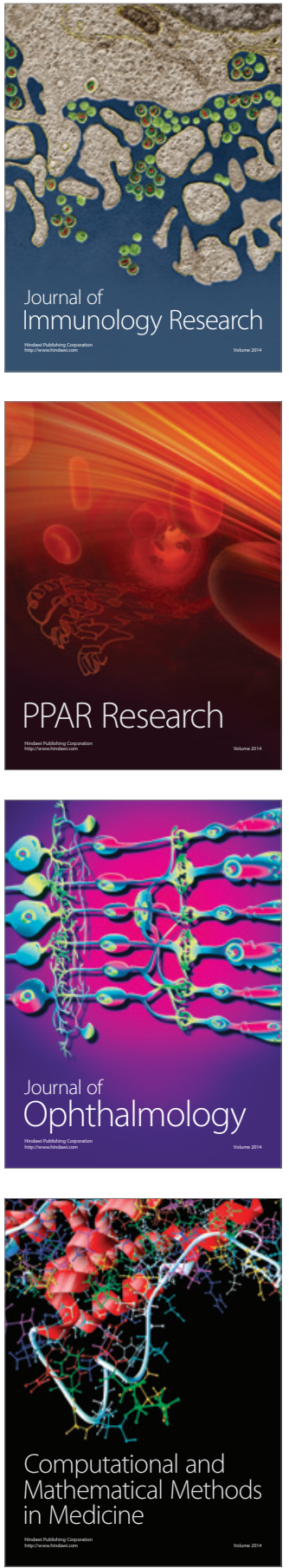

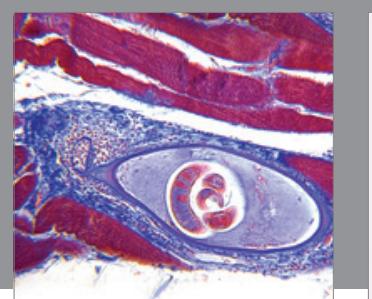

Gastroenterology Research and Practice

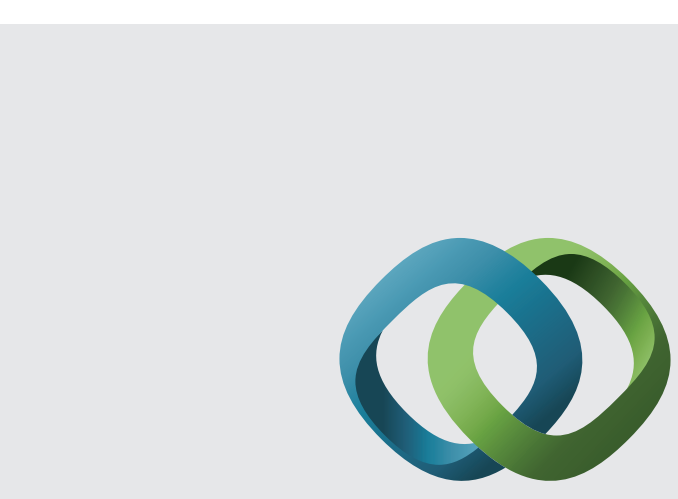

\section{Hindawi}

Submit your manuscripts at

http://www.hindawi.com
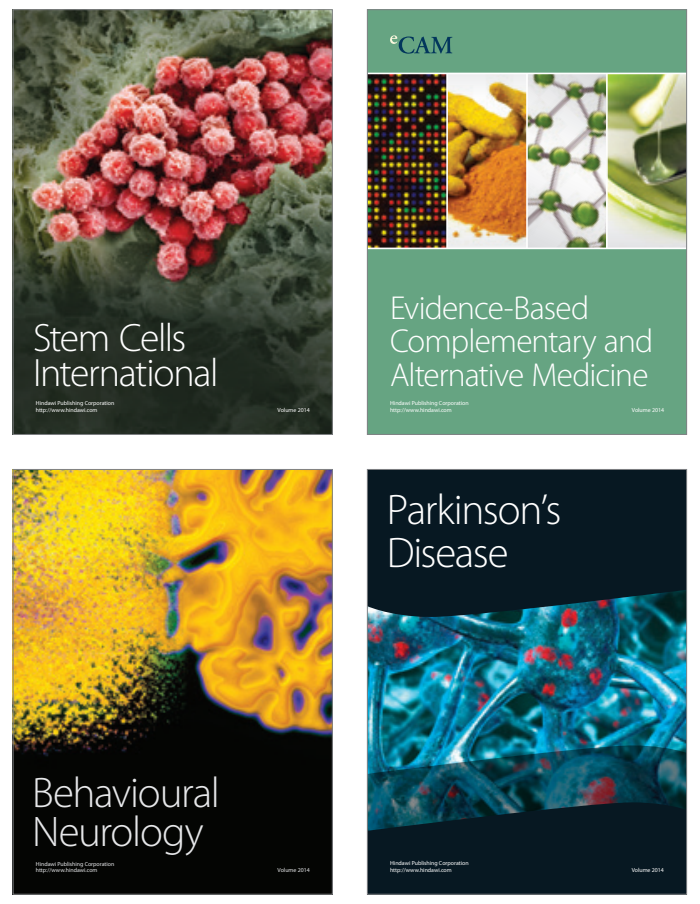
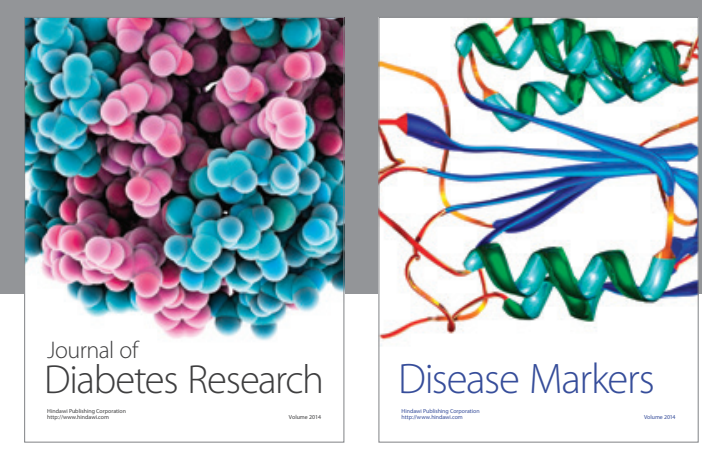

Disease Markers
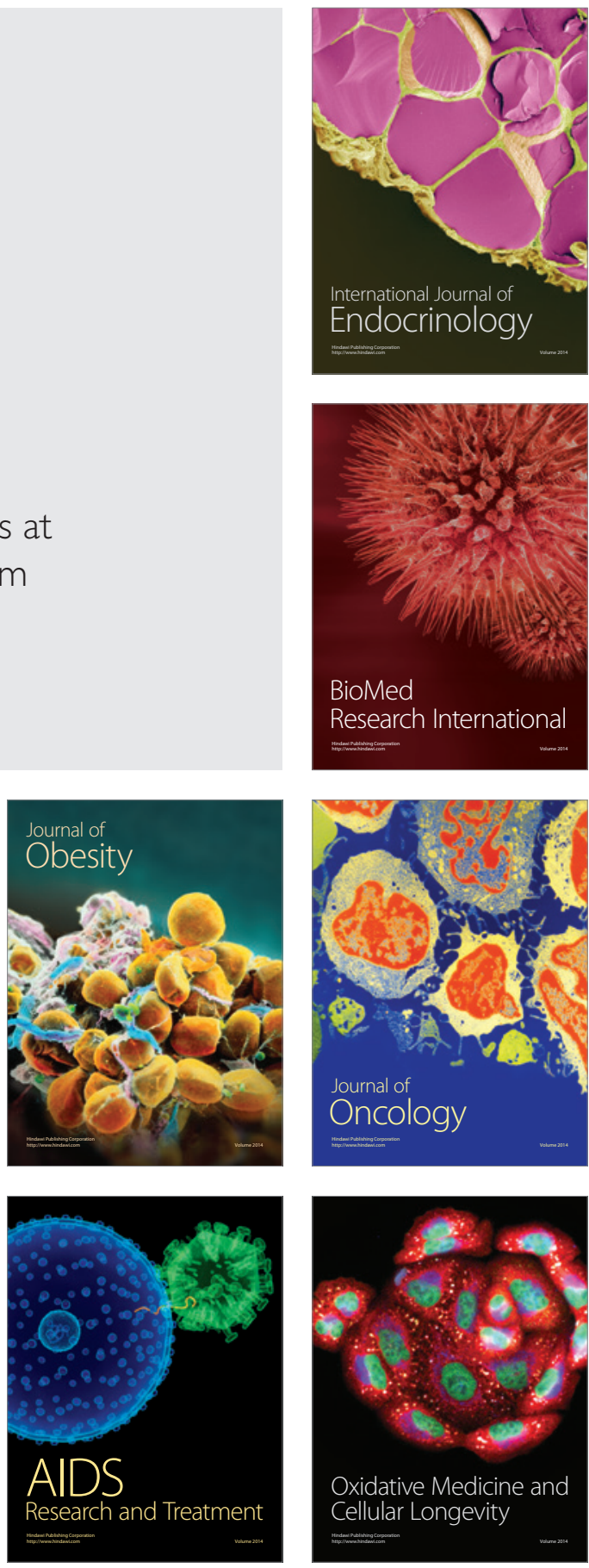